\title{
CONTRIBUIÇÕES HABERMASIANAS PARA UMA ÉTICA INTERCULTURAL DA INFORMAÇÃO: APROXIMAÇÕES
}

\author{
Jorge Atilio Silva Iulianelli \\ PPG Educação/UNESA \\ Doutor em Filosofia pelo IFCS/UFRJ \\ Coordenador da Linha de Pesquisa Política, Gestão e Formação de Educadores \\ Editor do Blog Observatório Fluminense do PNE \\ (observatoriofluminensepne.blogspot.com.br). \\ silva.iulianelli@gmail.com
}

\begin{abstract}
Resumo
Este artigo é uma reflexão sobre contribuições habermasianas à ética da informação. A questão da ética da informação continua a ser problemática. Ela deve ser coordenada desde que paradigma de relações interculturais? O caráter eurocêntrico das ciências da informação tem sido problematizado, sobretudo em relação aos regimes de verdade que se produzem na ciência e na tecnologia. O que significa a produção de conhecimento e a troca de saberes de caráter emacipatório para a ciência da informação? Embora essa questão não tenha sido abordada diretamente por Habermas, há elementos de sua investigação que podem trazer contribuições relevantes. Em diálogo como González de Gómez, Albagli, Capurro e Floridi oferecemos alguns elementos da reflexão habermasiana ao tema. Os conceitos de aprendizagem comunicativa e liberdade comunicativa podem ter amplo interesse para uma ética intercultural da informação.
\end{abstract}

Palavras-chave: Ética intercultural da informação. Ética do discurso. Habermas.

\section{HABERMASIAN CONTRIBUTIONS TO AN INTERCULTURAL ETHICS OF INFORMATION: APPROACHES}

\begin{abstract}
This article is a reflection on habermasian contribution to information ethics. The question of an ethics to information is still problematic. Which paradigm is driven this information ethics, an Eurocentric or an Intercultural one? This is a central question because of the truth regime producing science and technology. What means an emancipatory paradigm of knowledge production and interchange of wisdom towards an ethics of information? Hence these questions are not treated directly by Habermas, there is some elements of his reflection contributive to this issue. This article dialogues with González de Gómez, Albagli, Capurro and Floridi, offering some habermasian contribution, as concepts like communicative learning and communicative freedom, which seems relevant to an intercultural ethics of information.
\end{abstract}

Key-words: Intercultural ethics of information. Discursive ethics. Habermas.

\section{Conhecimento, informação e sociedade: investigações ético-políticas}

Os processos públicos de comunicação são tanto mais isentos de distorções quanto mais estiverem entregues a uma sociedade civil oriunda do mundo da vida. (Jürgen Habermas, Faktizität und Geltung) 
Compartilho com González de Gómez $(2011,183)$ a compreensão de que as relações entre política, economia e informação são tradicionais. São relações que se estabelecem por deslocamentos, frutos dos atores sociais, por meio de seus interesses manifestos, numa esfera pública em disputa (agonística), para tornar democrática a vida em sociedade. Parece que não podemos negar os vínculos entre os pares, democracia, liberdade e informação, conhecimento. Bem como, necessitamos afirmar os vínculos entre alterações socioeconômicas e as inovações tecnológicas, em especial quando as tecnologias da informação e comunicação (TICs) estão no centro mesmo dessas mudanças. As questões que pretendemos contribuir a aprofundar dizem respeito, sobretudo, à Ética Política do Conhecimento e da Informação. São questões procedimentais, tais como:

(i) Qual o grau de representação política (GONZÁLES DE GÓMEZ, 2012; FRASER, 2016; HABERMAS, 1981; SHIRKY, 2012) é razoável considerando o uso das TICs, também, pelos movimentos sociais? Maior acesso aos meios e, até mesmo, apropriação dos usos e das tecnologias, amplia a possibilidade de controle social dos media poder (sistema administrativo) e dinheiro (sistema econômico) ou ratifica os efeitos de apartação social?

(ii) Esses dispositivos se abrem para a produção de conhecimento emancipatório, intermediados comunicacionalmente, por meio da disseminação de tecnologias sociais (LOVINK, ano; HABERMAS, 1981; GONZÁLES DE GÓMEZ, 2012)? Empoderam as populações vulneráveis (LOVINK, 2012)? Ou as estrutura do sociometabolismo capitalista do Capital (MÉTZAROS, 2002) são reproduzidas e cristalizadas por meio dessas novas tecnologias (LOVINK, 2012; HARDT, NEGRI, 2005);

(iii) Quais contribuições emergem da identificação das normatividades fracas que interagem na constituição das relações em rede, e de relações de redes entre redes?

Dado o objetivo desse ensaio e a necessidade de indicar referenciais teóricos, princípios metodológicos e horizontes epistêmicos e éticos da investigação, o primeiro eixo de questões receberá maior atenção. Os demais eixos, também, relevantes e pertinentes, são necessários a uma ética-política da informação que siga as trilhas das investigações habermasianas, em diálogo com o pensamento intercultural. Destacaremos, no que segue, reflexões sobre as relações entre apropriação do conhecimento e a noção unitária da ontologia do conhecimento. Apelaremos para tanto ao referencial habermasiano, sobretudo ao desenvolvimento das argumentações elaborado em Warheit und Rechtfertigung. 
Concluiremos discutindo a relevância desta discussão para a afirmação da democracia deliberativa e da ética intercultural da informação.

\section{2 Ética, Política e Ciência da Informação: contribuições na perspectiva habermasiana}

Suave, mari magno tubantibus aequora ventis, e terra magnum alterius spectare laborem [...] (Lucrécio, Rerum Natura)

É consensual entre especialistas a afirmação da existência de um novo modo de produção capitalista (ALBAGLI; MACIEL, 2011, dentre outros). Neste modo de produção há (i) a centralidade da informação e da comunicação nos padrões científicos e tecnológicos das inovações socioindustriais; (ii) e o reconhecimento do aumento do poder no controle desses intangíveis (ALBAGLI; MACIEL, 2011). Esse contexto justifica o debate sobre as atuais condições e o papel das novas dinâmicas interativas na produção e circulação de conhecimentos e informação, bem como seu papel na criatividade e inovação. Poder-se-ia afirmar que há a mutação do ethos comunicacional da sociedade contemporânea (CAPURRO, 2010, p. 12).

Como observa González de Gómez (2011, p. 48), “as molduras normativas e as ações de informação formam parte importante do domínio investigativo das ciências da informação". Nessa economia baseada em conhecimento, cada vez é mais relevante a produção, distribuição e processamento de conhecimento, atividade denominada de trabalho imaterial. Os processos de aprendizagem vão se tornando localizados, por meio de conhecimento tácito, ampliando os efeitos da exclusão digital. Se Capurro está certo, no entanto, ao afirmar que o atual espaço digital é fomentador de diálogo, com a assim chamada web 2.0, então, seria relevante observar como a superação da razão prática pela razão comunicativa nos facultaria uma cultura digital inclusiva e participativa.

Dentre as várias possibilidades, as questões referentes ao acesso livre à informação e à governança das redes digitais (e seus efeitos para o controle social dos media poder/sistema administrativo e dinheiro/sistema econômico), parecem ser apropriadas a um projeto de pesquisa ético-política das ciências da informação. Trata-se de investigação que perquira a dimensão representacional da justiça. Faço aqui uma menção à análise de Nancy Fraser (2009) que considera necessário a esse novo momento de política midiática, que tenhamos no horizonte da justiça, além das dimensões distributiva (socioeconômica) e de reconhecimento (identidade, status), aquela propriamente política, a dimensão representacional. 
$\mathrm{Na}$ verdade, na medida em que Habermas propõe uma democracia deliberativa (HABERMAS, 1999), toma em consideração essa dimensão política da justiça. Acerquemonos das pretensões de validade da ação comunicativa, como formuladas por Jürgen Habermas (HABERMAS, 1981): verdade, veracidade, sinceridade e expressividade; podemos notar que a carga normativa dos atos linguísticos, de forma muito significativa e fraca, estão aí presentes e alimentam os processos de aprendizagem comunicativa, por meio dos quais a espécie desenvolve suas interações e institucionalizações.

\section{Alguns temas habermasianos de informação e conhecimento}

Considerando que as atuais mudanças produtivas têm sua centralidade nas novas tecnologias de informação e comunicação, até que ponto os atuais meios técnicos disponíveis possibilitam maiores e melhores condições de acesso e disseminação do conhecimento e da informação? Essa indagação nos lança diante de um dilema que bem descreve a realidade contemporânea. Por um lado, existem mais condições e meios para acesso e disseminação de conhecimento capaz de cooperar para maior produtividade e competitividade, bem como favorecer a respostas às crises contemporâneas (ambientais, financeiras, civilizacionais). Por outro lado, a informação e conhecimento terminam por ser trabalho imaterial e mercadoria privatizada, retroalimentando os polos dominadores da plutocracia e isolando, ainda mais, os indivíduos, que consomem o conhecimento e a informação como mercadorias (ALBAGLI; MACIEL, 2011, p. 20-21).

Para países como o Brasil, esse dilema aponta para uma questão profunda. Será o nosso projeto democrático capaz de superar os processos continuados de apartação social (BUARQUE, 1994)? Teremos condições de superar o que afirma Quevedo (apud ALBAGLI; MACIEL, 2011, p. 31) em relação aos processos de acumulação do capital? Segundo ele, conquanto ciência e tecnologia modifiquem o modo de produção, não alteram substantivamente os processos de acumulação da riqueza e aprofundamento das desigualdades sociais e planetárias.

Albagli e Maciel $(2011,31)$ propõem que políticas de apropriação da informação e do conhecimento seriam mais eficazes que políticas de inclusão digital, concebidas como maior oportunidade de acesso aos meios. Essa política de inclusão digital está calcada, quase exclusivamente, no princípio de justiça distributiva. A reflexão de Albagli e Maciel é análoga ao que Nancy Fraser reconhece como déficit de reconhecimento, por um lado, na medida em que não há a afirmação da alteridade, e déficit representacional, por outro (FRASER, 2004). 
Para Albagli e Maciel (2011, p. 32), a apropriação reveste-se "de maior proatividade", tanto no sentido de capacitação para o uso das novas tecnologias, como no da produção das mesmas. Essa perspectiva, a partir dos interesses dos vulnerabilizados, lhes consideraria na condição de participantes. Esses dilemas inscrevem um conjunto de questões que interessariam a investigações da ética da informação. Outro problema seria até que ponto essa socialização do acesso e disseminação da informação e do conhecimento é equalizadora, na medida em que determinados conhecimentos, tais como know-how e know-who, são caracterizados por ele como conhecimentos tácitos, e não podem ser codificados.

Pinheiro (2005, p. 13-48) nos ensina que o processo de definição do campo do saber Ciência da Informação não teve (tem?) uma definição unívoca. Porém, se opta epistemologicamente considerá-la como uma ciência social, que lida com a recuperação da informação (dos conhecimentos científicos, compreendidos como conhecimentos explanatórios da natureza e da sociedade), com as novas tecnologias da comunicação e informação e com as relações sociais inerentes a esse processo.

González de Gómez (2012, p. 18) ressalta que, a opção epistemológica e heurística de tratar a Ciência da Informação a partir da gramática das ciências sociais, faz pensar a informação como elemento comunicacional, a partir dos usos sociais da linguagem. Quais contribuições ofereceria uma ética do discurso a uma teoria da apropriação como melhor política de acesso e disseminação da informação? No que segue indicaremos como uma perspectiva epistemológica e ética monista fraca, pode responder esse questionamento.

Nosso mundo social está submerso na linguagem, todas as vezes que nos expressamos temos a pretensão de fazer-nos entender sobre algo no mundo. Esperamos que o outro falante realize um reconhecimento intersubjetivo. Nesse sentido, podemos afirmar haver uma conexão interna entre representação de fatos e boa comunicação. Essa lógica do conhecimento como compreensão e observação pode contribuir para ampliar a apropriação da informação e do conhecimento? Isso implica no deslocamento da noção da verdade.

Passa-se de uma concepção solipsista, na qual o indivíduo reconhece a verdade mentalmente, para uma noção interativa: se algo é verdadeiro, é porque é racional e publicamente justificável. Compreender, pois, significa saber como alguém poderia se servir de uma proposição para se entender com alguém sobre alguma coisa. Então, as funções de comunicação e representação, presentes na linguagem, são co-originárias. Essas reflexões têm consequências para uma teoria do conhecimento científico, assim como para a teoria moral e do direito. Há pretensões de validade do discurso que são erguidas pela primeira pessoa, como 
participante, e na expectativa da segunda pessoa com quem se estabelece a comunicação (pragmática da linguagem).

Se aceitarmos que comunicar e representar, esses dois fins primários da linguagem, estão conectados internamente, o papel da segunda pessoa fica ressaltado, e a verdade como uma conquista de mútua interpretação, também superaremos, assim, a dicotomia internalismo/externalismo (GONZÁLEZ DE GÓMEZ, 2009). Será que aprendemos cognitivo-moralmente, nas interações humanas, e cognitivamente em nossa relação com o mundo? Essa é a perspectiva dicotômica que se encerra em um dualismo, no qual se estabelecem tarefas distintas para a práxis linguística.

Haveria o entendimento deôntico e a possibilidade de previsões relativas ao mundo natural. Segundo Habermas, uma vez que estamos vivos, não há como deixar de estarmos abertos a aprender. E a aprendizagem, como parte de nossa vida, é falível e tem efeitos notáveis em nossas descobertas. Enunciados verdadeiros são, pois, possibilitados a partir de nossa convivência e de nossas relações socioculturais. Se aceitarmos que existe uma relação intersubjetiva entre falante e ouvinte, aceitaremos que o ato de fala é uma relação, também,

objetiva com o mundo. Ao aceitar, por hipótese de trabalho, que o fim da argumentação é o entendimento mútuo, precisamos aceitar que representar, comunicar e agir são co-originários.

Segundo Habermas (2004, p. 7-62), no contexto da virada linguística, precisamos considerar que o conhecimento, até mesmo o conhecimento científico, é estabelecido em um contexto de comunicação. Na perspectiva dualista monológica, dicotômica, que assume, porém, a virada linguística, foi mantida a distinção entre compreensão e observação. Quando se rompe com o mito do dado, que acreditava que o conhecimento provinha da experiência sensorial (indutivismo ingênuo), toda relação com a realidade (interna e externa) é analisada como mediada pela linguagem, essa dicotomia pode ser, então, subsumida.

Porém, ao manter-se o mito do dado, do ponto de vista da observação, estaremos sempre remetidos a uma experiência de segunda ordem (uma comunicação linguística de uma experiência sensorial). Essa experiência é apenas possível por meio de um agente solitário. Até mesmo em relação a uma ação dirigida a um fim, uma ação instrumental (p.ex. o desenvolvimento de uma ferramenta, ou de um plano de negócios), a qual se comprovaria por meio de seu sucesso/fracasso, haveria discursos, do ponto de vista do observador (terceira pessoa), que permitiriam, nessa concepção, interpretações corretas.

Os processos de aprendizagem científica, porém, são impulsionados por decisões que a práxis do dia-a-dia exigem. Então, o que cabe ser explicado, por uma teoria do conhecimento pós-indutivista, é o processo de aprendizado, ativado pela problematização 
daquilo que é esperado para orientar nossa ação. Isso torna relevante o conjunto das práticas sociais que se entrelaçam, constituindo uma forma de vida. Todas as esferas de nossa experiência podem ser probematizadas, nossa vida comum, nossa vida social, nosso mundo da vida, podem estar em questão.

Igualmente, as respostas epistemológicas a essas problematizações podem ser elaboradas por diferentes práticas cognitivas. Considere, nesse contexto, a noção de mundo da vida. Ele envolve distintas práticas que respondem a regras. No mundo da vida somos atores, interagimos na constituição de nossa personalidade, entre agentes (sociedade) e com o mundo objetivo. Há ações não-linguísticas que também respondem às regras da linguagem. E essas ações são do tipo social ou não-social. O agir social é aquele dirigido à interação, que é regida normativamente, entre sujeitos que desejam se comunicar (interação, agir comunicativo) ou subordinar uns aos outros a partir de uma determinada influência estratégica mútua (agir estratégico).

Decorre da descrição dos tipos de ação, regidas por regras, a necessidade de justificação da própria ação, por parte dos atores sociais, ou agentes comunicativos. Ou seja,

para justificar as próprias ações os agentes deverão, de alguma maneira, dominar as regras das próprias ações. Quando as regras não são compreendidas, ou mal compreendidas, a imputação de responsabilidades fica comprometida. Não há possibilidade de sanções, ninguém nos pune, nem nós mesmos podemos nos punir se as regras que devem ser seguidas não são compreendidas.

Porém, ações sem justificativas por incompreensão não correspondem ao tipo ações sociais. Outra explicação se faz necessária, na qual seja possível identificar a unidade do mundo da vida, na pluralidade de suas vozes. Quando empregamos ou regulamos nosso conhecimento tecnológico, há uma normatividade particular que rege esse processo. Essa é a normatividade cognitiva que mensura o conteúdo proposicional e sua pertinência, por meio de regras que permitem uma intervenção instrumental. Isso é o que permite avaliar o conhecimento pelo resultado afirmativo ou negativo, sucesso ou erro.

E isso depende da interlocução com outros que podem confirmar ou negar nossas assertivas, mostrando nosso erro. Quando é o caso, isso nos obriga a aprender mais. Essa é uma consequência normativa holística, que se aplica tanto à correção moral, quanto à coordenação de ações com fins tecnológicos. Essa é a condição de aprendizagem comunicativa da espécie humana.

Ou seja, se acrescentarmos à perspectiva da guinada linguística a aporia kantiana entre o mundo dos valores e o mundo dos fatos, haverá uma distinção linguística entre a 
normatividade deontológica e a normatividade cognitiva. Essa acepção de dois mundos não é aceitável desde uma perspectiva naturalista fraca do mundo da vida. Se aceitarmos que somos seres vivos em evolução, e que nossa condição inclui a capacidade linguística, de comunicação, isso traz a consequência referente à nossa capacidade de agir e conhecer como parte dessa nossa condição, mediada por essa nossa condição.

A aceitação da existência de uma arquitetônica do mundo da vida supõe interações cognitivas e cognição do mundo objetivo. Essa assunção indica que o dualismo metodológico, do compreender e do observar, está equivocado. O direito favorece à superação de conflitos, bem como o direito pode ser articulado como instrumento de afirmação de interesses unilaterais. Ora, como a perspectiva consensualista habermasiana oferece argumentos suficientes para a afirmação do papel de superação de conflitos inerentes ao direito? Em segundo lugar, como a teoria da tolerância, à lá Habermas, suporta a possibilidade de uma interação internacional, na qual as diferentes posições religiosas são apresentadas como ameaça à afirmação de direitos humanos universais?

A ênfase cognitiva na necessidade de abertura epistêmica das mundividências religiosas, concomitante à afirmação do direito à cidadania a partir da mundividência religiosa, constitui um terreno fértil para investigar os processos mundiais de criminalização e demonização de perspectivas religiosas por visões políticas de mundo, e de perspectivas políticas de mundo por visões religiosas, como possíveis de serem superadas - para além do diálogo entre surdos (problema da tradutibilidade). Ou seja, nossas reflexões buscam afirmar que a perspectiva de Habermas, quanto ao direito, faculta uma compreensão do funcionamento do processo democrático como um malabarismo entre os interesses do Capital e os interesses dos cidadãos vulnerabilizados.

No limite, a perspectiva de Habermas não sustenta teses anquilosadas de um liberalismo político privatista, do self made man americano, ou dos entitlements de um Dworkin (2007) (ou mesmo de um Nozick). Ao contrário, identifica a necessária complementaridade entre uma cidadania privada e uma cidadania política. O problema é o da aprendizagem comunicativa necessária aos comportamentos democráticos. Isso implica no reconhecimento mútuo das capacidades cognitivas de todos os envolvidos, e do papel do Estado em favorecer o diálogo entre os processos de autorreflexão das comunidades seculares e religiosas.

O limite que está colocado para as comunidades religiosas é que elas têm que estar abertas aos processos de aprendizagem e autocorreção. Desenvolvi o argumento de que as comunidades religiosas abertas aos processos de aprendizagem modernizadores terão que 
cumprir o papel de opor às visões ortodoxas e fundamentalistas argumentos teológicos, opostos a argumentos teológicos. Por isso, todos os cidadãos devem opor argumentos históricos e epistêmicos a argumentos históricos e epistêmicos erguidos por esses contendores. Ou seja, no limite, para Habermas, a possibilidade da convivência cooperativa em sociedades multiculturais, nas quais há pluralismo religioso, se dá pela superação do paradigma normativo do liberalismo político, pela perspectiva de uma teoria política cognitivista.

A concepção de democracia deliberativa que Habermas desenvolve por estas questões da gênese da relação entre sociedade e Estado se oporá às perspectivas contratualista (liberal) e comunitarista (republicana). A visão contratualista, afirma que a sociedade possui um direito que é positivo, cogente e estruturado individualisticamente. Nele impera a noção de dominação das leis (rule of law). A visão clássica, republicana, o direito é a expressão da vontade dos cidadãos reunidos. $\mathrm{O}$ poder das leis exige que a formação democrática não se contraponha ao poder das leis, inexistindo corte entre a soberania popular e o direito.

Ficam a discutir entre si qual a prioridade, na linguagem de Habermas, entre a

liberdade dos modernos e a liberdade dos antigos: "O que deve vir antes: os direitos subjetivos de liberdade dos cidadãos da sociedade econômica moderna ou os direitos de participação política dos cidadãos democráticos?” (HABERMAS, 2007, p. 154). Para contratualistas, a autonomia privada dos cidadãos é imutável e é assegurada pelas leis, se traduz em direitos fundamentais.

Para os comunitaristas, a autonomia dos cidadãos é parte da auto-organização de uma comunidade que cria suas próprias leis. Pois, são estas alternativas falsas. O dilema está mal apresentado. Trata-se, na verdade, de uma relação complementar entre autonomia privada e pública. Nós somos formados para sermos, de algum modo, capazes de nos autogovernar, no sentido de termos uma ação subjetiva que é igualmente distribuída entre todos. Temos cidadania (esfera pública) com esfera privada articulada simetricamente. Esta é uma intuição partilhada pelos membros das sociedades complexas contemporâneas. Esta intuição está à base da formação racional da vontade. Isso nos faz relacionar a vontade (individual) à nossa autolegisferação.

O processo democrático é um processo de aprendizagem comunicativa, no qual nos tornamos intérpretes morais. A superação do suposto paradoxo entre contratualismo e comunitarismo se dá por meio de uma avaliação adequada desse modelo de democracia deliberativa que se forma por meio da aprendizagem e da liberdade comunicativa. 


\section{Para continuar a reflexão...}

Há muitas homologias entre o pensamento de Habermas e o de Luciano Floridi. No intuito de avançar a reflexão ao redor da questão intercultural da ética da informação parecenos necessário levar a reflexão a esse ponto de diálogo. Para Floridi é necessário distinguir entre uma ética da comunicação global e uma ética da informação global (FLORIDI, 2009; FLORIDI, 2010). Respectivamente, se referem uma às práticas de diálogo e construção de consensos de forma interativa na relação intercultural, a outra cuidaria de questões pragmáticas, tais como aquelas referentes aos princípios éticos diretores de tal diálogo e as razões para sua escolha. Ambas permitiriam a discussão sobre o referencial ético que orientaria a ética da informação global, deontológica, contratualista, comunitarista (FLORIDI, 2009).

Floridi utiliza um conceito, para ele, fundamental: "ontologia compartilhada" (shared ontology); o que mostra haver para ele um problema hermenêutico da ontologia (compreensão ou incompreensão). Quando linguagens e visões de mundo procuram partilhar informações

pode haver um problema de tradutibilidade - vale recordar que Habermas chama atenção para este problema no que se refere às relações entre cultura religiosa e cultura política, por exemplo (HABERMAS, 2007). A solução da tradutibilidade estaria naquela dimensão básica da ontologia, na qual resolvemos a vida e a morte, tudo o que atende à vida e evita o sofrimento (comida, abrigo, angústia, proteção, etc.) - o que parece extremamente correlato ao conceito habermasiano de mundo da vida. A noção de mundo da vida (lebenswelt) resgata a dimensão cotidiana, comunicativa, na qual como agentes livres, comunicativos, interagimos, partilhamos nossa solidariedade intersubjetiva.

Floridi, de certa forma resgatando o conceito de ontologia heideggeriano - também retomado por Habermas em Verdade e Justificação (HABERMAS, 2004). Essa ontologia ontocêntrica assume que o agente é secundário ao paciente (quem sofre a ação). Isto inclui aos seres vivos, ou seja, trata-se de uma ontologia centrada na vida que sofre. Como Heidegger, ele se opõe a uma ontologia que fosse a busca da essência do ser, ao contrário, ele quer identificar o modo de ser do ser e de suas relações entre os seres. Tal ontologia o habilita a afirmar uma ética da interação, que seja a ética da informação global. Ela não pretende impor valores, ou hierarquia de valores. Esta ética de valores, como Floridi concebe, segundo ele “não é a declaração dos direitos humanos" (FLORIDI, 2009, p.229). Isto implica na afirmação de uma dignitas terrae, uma dignidade de todos os seres vivos, não apenas os seres humanos. Aqui o ponto de vista de Floridi, ao nosso ver, coincidente ao de Habermas, é o dos desafios 
trazidos pela vida malograda. Para Habermas, o empreendimento ético, sempre procedimental, tem o papel de impedir ou reduzir o sofrimento. Exatamente o sofrimento é o elemento, considerado por Floridi, o mais fundamental (FLORIDI, 2008). É a entropia, o sofrimento, que deve ser evitado.

Talvez cause espécie não abordar a oposição entre uma visão das relações entre entes humanos e não-humanos como um elemento desestabilizador dessa homologia ora apresentada. É que nosso objetivo é tão somente indicar a possibilidade de um diálogo profícuo entre a teoria habermasiana da ação comunicativa, com seus desdobramentos da liberdade e da aprendizagem comunicativa, como ferramentas teóricas para refletir sobre o papel das tecnologias e da ciência da informação, em diálogo com a ontologia ontocêntrica de Floridi. Tais oposições não nos renderiam, neste momento, elementos de avanço teórico.

Talvez, nenhum dos dois autores fique muito feliz com essa interpretação. Não parece, entretanto, discrepante notar que as noções de mundo da vida, ética do discurso, consideração por todos os concernidos - o que, segundo Habermas, envolve, também, o meio ambiente, seriam conceitos passíveis de homologias interessantes para uma ética da informação

intercultural, como a proposta, dentre outros, por Floridi. É verdade que há discussões que identificam as dessemelhanças entre uma ética intercultural e a ética do discurso, assim como aspectos que Floridi desenvolve muito alheios ao que Habermas propõe, e vice-versa, deixemos, entretanto, tais considerações para futuras ocasiões.

\section{Referências}

ALBAGLI, Sarita; MACIEL, Maria Lúcia. Informação, conhecimento e poder: mudança tecnológica e inovação social. Rio de Janeiro: Garamond, 2011.

\section{BOLAÑOS}

BUARQUE, Cristóvão. A revolução nas prioridades. São Paulo: Paz e Terra, 1994.

CAPURRO, Rafael; GUTIERREZ, Diana. Ética Intercultural de la información. 2010

Disponível em: 〈http://www.capurro.de/reforma.html>. Acesso em: 16 ago. 2012.

DWORKIN, R. O imperio do direito. São Paulo, Martins Fontes, 2007.

FLORIDI, Luciano (Ed.). The Cambridge handbook of information and computer ethics. Cambridge University Press, 2010.

FLORIDI, Luciano. Information ethics. Its nature and scope. In: HOVEN, Jeroen van den; Wecker, John (Ed.). Information technology and moral philosophy. Cambridge:

Cambridge Univ. Press, 2008, p. 40-65. 
FLORIDI, Luciano. Information ethics and globalization. In: GLOBAL FORUM CIVILIZATION AND PEACE, 2009, Seul, Proceedings... Seul: Academy of Korean Studies and Korean National Academy for Unesco, 2010, pp. 217-230.

FRASER, Nancy. Reenquadrando a Justiça em um mundo globalizado. Lua Nova, v. 77, p. 11-39, 2009. Disponível em: < http://www.scielo.br/pdf/ln/n77/a01n77.pdf >. Acesso em: 21 ago. 2016.

FREIRE, Gustavo Henrique de Araújo (Org.). Ética da informação: conceitos, abordagens, aplicações. João Pessoa: Ideia, 2010. Disponível em:

<http://ru.ffyl.unam.mx:8080/bitstream/10391/1328/1/teaching\%20information\%20ethics.pdf $>$. Acesso em: 16 ago. 2012.

GONZÁLEZ DE GÓMEZ, M. N. As ciências sociais e a questão da informação. Morpheus Revista Eletrônica de Ciências Humanas, v. 9. n. 14, p. 18-37, 2012, Disponível em: <http://www.unirio.br/morpheusonline/numero14-2012/artigos/nelida_pt.pdf $>$ Acesso em: 18 ago. 2012.

GONZÁLEZ DE GÓMEZ, M. N. Informação, conhecimento e poder: do ponto de vista das relações entre economia, política e linguagem. In ALBIGALI, Sarita; MACIEL, Maria Lucia (Org.). Informação, conhecimento e poder: mudança tecnológica e inovação social. Rio de Janeiro: Garamond, 2011, pp. 183-210.

HABERMAS, Jürgen. A reinvenção contemporânea da informação: entre o material e o imaterial. Tendências da Pesquisa Brasileira em Ciência da Informação, v. 2, n.1, p. 0121, jan./dez. 2009. Disponível em:

<http://inseer.ibict.br/ancib/index.php/tpbci/article/view/19/41>. Acesso em: 16 ago. 2012.

HABERMAS, Jürgen. Direito e democracia: entre facticidade e validade, v.2 [Faktzität und Geltung, Beiträge zur Diskurstheorie des Rechts und des demokratischen Rechtsstaats]. Tradução de. Flávio Beno Siebeneichler. Rio de Janeiro: Tempo Brasileiro, 1999.

HABERMAS, Jürgen. Entre naturalismo e religião: estudos filosóficos. Tradução de Flávio Beno Siebeneicher. Rio de Janeiro: Tempo Brasileiro, 2007.

HABERMAS, Jürgen. Theory of communicative action, v.2 [Theorie der Kommunikative Handelns]. Translation by Thomas McCarthy. Boston: Beacon Press, 1981.

HABERMAS, Jürgen. Verdade e justificação. [Warheit und Rechtifigung]. Tradução de Milton Camargo Mota. São Paulo: Loyola, 2004.

LOVINK, Geert. Networks Without a Cause: A Critique of Social Media. Cambridge and Malden, Polity, 2012.

MÉTZAROS, Iztvan, Para além do Capital. São Paulo, Boitempo, 2002.

HARDT, Michel; NEGRI, Antonio. Imperio. São Paulo, Record, 2005.

PINHEIRO, Lena Vania Ribeiro. Processo evolutivo e tendências contemporâneas da Ciência da Informação. Informação \& Sociedade: Estudos, João Pessoa, v.15, n.1, p.13-48, 2005. 
Filosofia da Informação

Disponível em: <http://www.ies.ufpb.br/ojs2/index.php/ies/article/view/51/1521>. Acesso em: 18 ago. 2012.

SHIRKY, C. Lá vem todo mundo: o poder de organizar sem organizações. Rio de Janeiro, Zahar, 2012. 